\title{
Fake news, fake science - the black side of the internet
}

\author{
Jean-François ROULET \\ DDS, PhD, Drhc, Prof hc, Professor \\ Editor-in-Chief

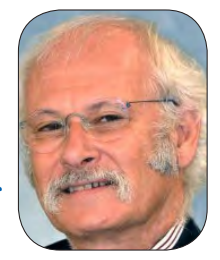

Dear readers,

The internet is a fantastic world. It is an unbelievably deep source of information. On top of it, with the social media it gives to you access to basically millions of people. Sounds nice, doesn't it? But as a critical mind, 1 must ask myself: is this beneficial only? 1 doubt it. Since information is neutral, it can be good or bad, or in other words, true, false or even worse: manipulated. 1 definitely know that social media are used to target people in order to make business with them. The mechanism is simple: you create first a group of followers (the larger the better), then you feed them with a recommendation to buy something you want them to do in order to increase the profit of your institution. With so-called hashtags (\# name) you can throw out some concentrated slogans hoping to create a community of followers. The objective is to have the mass to ask for changes. All these mechanisms run independently, without anybody checking if the contents are true or false.

This summer, Germany has experienced a wave of news about fake science by German scientists. An international group of journalists had investigated the topic and the results were made public by the Süddeutsche Zeitung Magazin and the public broadcasters Norddeutscher Rundfunk (NDR) and Westdeutscher Rundfunk (WDR). The journalists evaluated 175,000 scientific articles by 5 of the most important pseudo-scientific platforms. They had successfully published numerous non-scientific papers, even computer-generated fake papers with these pseudo-scientific publishing platforms. Furthermore, they found that employees of big pharmaceutical companies had used these pseudo-scientific platforms to publish data (www.dw.com/en/germany-sees-sharp-risein-fake-science-journal-publications-report/a-44742014; www.ndr.de/dernndr/presse/More-than-50oo-Germanscientists-have-published-papers-in-pseudo-scientific-journals,fakesciencer78.html). The original report had been picked up by multiple news publications and had triggered a vast public discussion about this phenomenon, known for years, but no one had realized its gravity.

The reasons for this are the so-called predatory journals that take advantage of the pressure on scientists to publish. "Publish or perish" is still very valid. The traditional way of publishing is through well-known journals which have a well-established rigorous peer review process that functions as a quality control that guarantees the validity of the content. This process is sometimes painful and slow. The authors must react to the comments of their peers and modify their papers. Sometimes papers are rejected, which requires even more work and with a submission to another journal the process starts again, which means that publishing is hard work. These "traditional" journals are usually printed and financed by subscriptions mainly sold to university libraries. On the other side, there are the so-called open access journals. The idea of open access to knowledge is noble and at first glance correct. Readers get access via internet and are free to read online or download the content as pdffiles. 
However, someone must pay for the production costs, which are substantial, even if the journal is not printed. This approach has created a reverse of the fee structure. Usually, in open access journals, the authors must pay for their submission. With this vicious trade, a big problem was created. Publishers have very quickly realized that such an approach can easily make big money by keeping the effort low (minimal or no peer review process) publishing fast and requiring substantial submission fees. These so-called predatory journals are characterized by usually having names very similar to renowned journals, have the look of a serious journal, and have editorial boards, but very often the individuals are not known in the field. The predatory journals usually aggressively ask for manuscripts by contacting researchers via e-mail. The problem we are faced with now is "You simply don't know if the studies, which are published with open access journals are good, worthless, or bad, because you cannot be sure if and what kind of editorial process or peer review takes place there. That is the problem with the predatory publishers in the end: eroding trust in science. A slowly creeping poison. Something might look like a study, but is not worth the paper it is written on."(www.theguardian.com/technology/2018/aug/10/ predatory-publishers-the-journals-who-churn-out-fake-science). Unfortunately, since the world is not black and white, but a sum of grey shades, the situation is more complicated. There are open access journals that have a well-established and functioning peer review process, and therefore are publishing valid information. On the other hand, also "traditional" journals feel the economic pressure and 1 have noticed that sometimes they publish manuscripts that definitely could have been improved with relevant recommendations by reviewers. So what to do as a reader? First be very critical, when you read a paper. Check, if what you read makes sense, if you compare it to your knowledge, check if the language is correct and be suspicious, if everything is too smooth and if there are no figures. If in doubt, there is no way around the effort to look up the journal in the internet, check who is the publisher, the editor and who is in the editorial board. You should recognize some names of scientists that have a record of good contribution to the research field the journal is reporting about.

The sad reality is that everybody working in an academic institution or having the obligation of continuing education in his/her profession is confronted with this. So am 1 as well. This summer 1 got a new teaching assignment. Teaching students dental materials by reading the literature. For this class, every student must read 3 scientific papers and present a critical review of each paper as a power point presentation. My predecessor has assigned the papers from the literature of the years 2017 and 2018 to the students, a total of 276 papers. In order to be able to grade the students, 1 must read all these papers carefully as well and 1 was confronted with many journals unknown to me. Reading the papers with an editor's eyes revealed a scary amount of errors which should have been detected with a peer review process. Here are some examples: The reader cannot exactly understand what was done; for the methods used, the authors refer to other publications, however when looked up they were not found or showed different methods; poor experimental designs which do not allow to properly discriminate the different groups; wrong materials used that were not what the authors claimed; faulty statistics, or statistics reports that do not allow to see where the significant effects were, or no statistics at all; conclusions that were not based on the hard data of the experiment; poor discussions; or very poor English.

And finally, 1 got a sore finger from deleting all the requests by unknown journals to submit a paper or become a member of the editorial board and solicit papers. There is no day, where 1 do not get multiple requests. So far there was only bad news to report in this editorial. The good news is that yes Stomatology Edu] is an open access journal. It is even an exotic journal, since we print it as well. The very good news is that we have a rigorous peer review process and dedicated editors which improve the quality of manuscripts and eliminate errors. In the final phase, every manuscript is run through plagiarism software. And, 1 am proud to say that we rejected a paper that had been published already in Russian. This, dear readers is our commitment to you, so you can read valid content.

Sincerely yours,

J-FRoulet

Editor-in-Chief

DOI: 10.25241/stomaeduj.2018.5(3).edit.1 